\title{
Maximum power tracking control wind turbine based on permanent magnet synchronous generator with complete converter
}

\author{
Soumia EL HANI ${ }^{\mathrm{a}^{*}}$, Said GUEDIRA ${ }^{\mathrm{b}}$, Noureddine EL ALAMI ${ }^{\mathrm{c}}$ \\ ${ }^{a}$ Mohammed V Souissi University, ENSET BP 6207, Rabat Morroco \\ ${ }^{b}$ ENIM , Hadj Ahmed Cherkaoui Street, Agdal - Rabat Morroco \\ ${ }^{c}$ Mohammed V Agdal University, EMI Rabat, Morroco
}

\begin{abstract}
This paper discusses the problem of maximum power point tracking (MPPT) of Wind Turbine based on a permanent magnet synchronous generator (PMSG) connected to power grid trough complete static converter. To achieve this, we propose a control scheme of synchronous generator, consisting of a DC/AC device followed by a second DC/AC device. The idea behind MPPT principle is turbine speed variation depending on wind speed in case of generator indirect connection to power grid. Simulations on Matlab-Simulink can be found at the end of the paper, confirming a good consistency with study objectives of control scheme, selection of setting parameters and complete converter architecture.
\end{abstract}

Keywords: PMSG, wind turbine, complete converter, MPPT, pole placement

\section{Introduction}

With soaring fuel prices and predictable exhaustion of fossil fuels, alternative options are increasingly considered. The beginning of the 21 st century had been marked by a spectacular rush towards renewable energy conversion systems. The ultimate objective is to get away from dependence of conventional sources of energy. Recently, this trend increased, all the more, by considerations of ecological order. Indeed, the high consumption of the traditional fossil energy sources causes serious environmental damage. Thus, all countries are now called upon to contribute international effort to combat climate change. Among all the renewable energies, three main classes emerge: mechanical (sea swell, marine currents, wind, etc), electromagnetic (solar panels, etc) and thermal (geothermal, solar thermal, etc). In particular, wind power can be converted to mechanical power by water pumping or to electrical power by using appropriate generators. The latter form has expanded rapidly throughout the world, through both household and industrial applications in connection with power grid. In financial terms, the wind turbines have a low profitability [1], given the significant cost of installation. However, they have many advantages in terms of preserving non-renewable natural resources, limiting environmental pollution and operational autonomy.

Theoretically, recovering power of wind turbine generators is limited to approximately $59 \%$ of the kinetic energy of the wind [1]. This is the Betz limit. The power coefficient $C_{p}$, takes into consideration this limit as well as frictional losses and varies with the rotational speed of the turbine. That is why, monitoring of the operating point at maximum power is recommended. Many studies have been carried out on approaches of MPPT [2]. Generally, MPPT methods can be broadly classified into those that not use sensors and those that use sensors. Sensorless methods [3] rely on the monitoring of the power

\footnotetext{
* Manuscript received May 9, 2013; revised July 31, 2013.

Corresponding author. Tel.: +212 661260767; E-mail address: s.elhani@um5s.net.ma.
} 
variation. The others with sensors [3] are dedicated to researching the MPPT by control of turbine torque and specific speed, commonly known by TSR (tip speed ratio) [4], [5]. TSR control regulates directly the turbine speed or torque to maintain the TSR at an optimum value by measuring the turbine speed.

The adopted sensor method of MPPT requires real-time reading of wind speed as well as prior knowledge of wind turbine characteristics. It presents many advantages over HCS (hill climb search) method: fastness of convergence and greater stability of calculations at steady state [6]. The amount of energy recovered by conversion systems of wind energy (variable speed wind energy conversion system: VS-WECS), depends on the accuracy with which search of MPPT is done and also on the type of generator used. Energy conversion chains often use a permanent magnet synchronous generator [7]. This type of machine allows overcoming the problem of the excitation current supply, heavy to manage in a conventional synchronous machine.

To maximize the efficiency of the wind generator, various solutions were examined at different levels of conversion chain [7] according to direct or indirect grid connection. Indirect grid connection of the generator provides, in addition to the advantage of optimizing the extracted power from the wind, the opportunity to save significant starting and synchronizing time before the connection to the power grid.

The role of the power electronic interface, mounted between generator and grid, is to manage generator in order to extract the maximum of the power of the wind [8]. Ordinarily, conventional scheme of VS- WECS uses a controlled-rectifier. Indeed, Li et al [9] has proposed a control scheme of PMSG with PWM Controlled-rectifier. This device requires an important physical logistics (6 fully controllable switches).

This study presents a complete scheme of wind turbine connected to power grid, using Permanent Magnet Synchronous Generator. The voltage generated by PMSG is rectified using a three-phase passive rectifier followed by a buck DC/DC converter. This device converts the AC voltage to DC voltage. The main circuit composition of grid side converter is a Boost DC/DC converter and a current Source Inverter followed by an isolation transformer.

\section{Nomenclature}

Symbols:

\begin{tabular}{|c|c|c|c|}
\hline$\alpha$ : Duty cycle & $\beta$ : Pitch angle $\left({ }^{\circ}\right)$ & $C_{d}:$ Scale factor $(\mathrm{m} / \mathrm{s})$ & $C$ : Capacitance $(\mathrm{F})$ \\
\hline$C_{p}$ : Power coefficient & $\delta$ : Internal angle $(\mathrm{rd})$ & $f:$ Friction factor (N.m.s) & $\eta$ : Power efficiency \\
\hline \multicolumn{2}{|c|}{$F$ : Cumulative distribution function } & \multicolumn{2}{|c|}{$\phi$ : Generator flux amplitude $(\mathrm{Wb})$} \\
\hline I: Current (A) & $K$ : Factor, ratio & $L:$ Inductance $(\mathrm{H})$ & $P$ : Power $(\mathrm{W})$ \\
\hline \multicolumn{2}{|c|}{$J$ : Inertia of the power train $\left(\mathrm{kg} / \mathrm{m}^{2}\right)$} & \multicolumn{2}{|c|}{$\lambda$ : Tip Speed Ratio (TSR), Eigenvalue } \\
\hline$p$ : Pole pairs & p.u.: per unit & $R$ : Blade length $(\mathrm{m})$ & $r$ : Résistance $(\Omega)$ \\
\hline \multicolumn{2}{|c|}{$R_{s}:$ Resistance of armature $(\Omega)$} & \multicolumn{2}{|c|}{$\omega$. Frequency alternating current $(\mathrm{rd} / \mathrm{s})$} \\
\hline$s:$ Laplace variable & $t$ : Time (s) & $V:$ Voltage $(\mathrm{V})$ & $V_{v}:$ Wind speed $(\mathrm{m} / \mathrm{s})$ \\
\hline$\Omega:$ Rotor speed $(\mathrm{rd} / \mathrm{s})$ & \langle\rangle : Average rate ss & & \\
\hline
\end{tabular}

Indices:

0: Steady-state value; 1: Generator side, fundamental; 2: Grid side; C: Capacitor; D: Grid; d: Direct axis; f: form; G: Generator, Gearbox; 1: leakage; Max: Maximum; N: Nominal; m: magnetizing; P: PWM; q: quadrature axis; R: Rectifier; RMS: Root Mean Square; s: stator.

\section{Power Components}

The control scheme of PMSG, which we propose (Fig. 1), is a complete convertor between PMSG and power grid with an intermediate storage capacitor. The generator side device is a cascade circuit including an uncontrolled three-phase bridge rectifier and a buck chopper [2]. Compared to MLI rectifier solution, this one gives the advantage of reliability, performance and low-cost material.

However, the grid side device is a cascade circuit including a boost chopper and a current source inverter (CSI) followed by an isolation transformer (see Fig. 2 (b)). 


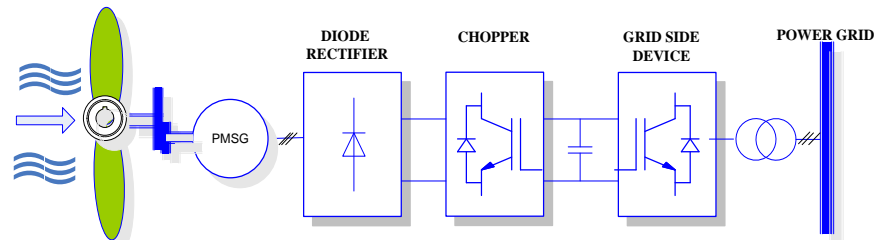

Fig. 1. Proposed VS-WECS global diagram.

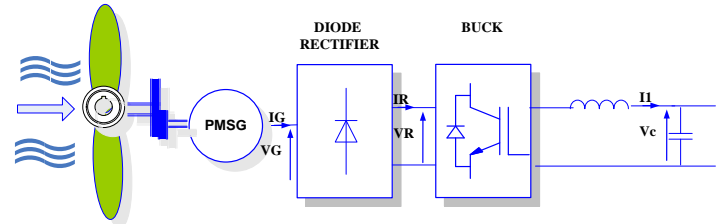

(a)

Fig. 2. Device of VS-WECS: (a) generator side and (b) grid side.

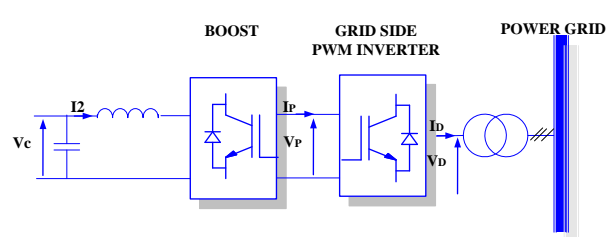

(b)

This means an instantaneous energy recovery enabling a battery saving with all that this implies in terms of environmental impact and maintenance management.

\subsection{Wind turbine model}

The wind turbine power is given by the expression:

$$
P_{E}=\frac{1}{2} \rho \pi R^{2} V^{3} C_{p}(\lambda, \beta), \quad \lambda=\frac{R \omega}{V}
$$

Maximum power extraction occurs at optimal TSR $\lambda_{\text {opt }}$ which gives $C_{\text {pmax }}$ well below Betz theoretical limit due to frictional and turbine design losses. Using a wind speed sensor, MPPT calculation module provides the generator speed reference so that we can extract maximum power. In order to assess the profitability of indirect connection equipment, it should be appropriate to perform a statistic representation of wind changes. The Weibull law provides the expression of the wind probability density distribution:

$$
f(V)=K_{f} C^{-K_{f}} V^{K_{f}-1} e^{-\left(\frac{V}{C}\right)^{K_{f}}}
$$

Rayleigh distribution is adopted by most wind turbine manufacturers, sets form factor value at 2 [10].

The cumulative distribution function is given by expression [10]:

$$
F(V)=1-e^{-\left(\frac{V}{C}\right)^{K_{f}}}
$$

$F(V)$ reflects the probability to have wind speed between 0 and $V$.

\subsection{Permanent magnet synchronous generator model}

Adopting generator convention in $d-q$ frame and the following assumptions:

- Negligible resistance of armature as well as transient time constants.

- Isotropic behavior of synchronous machine $\left(L=L_{d}=L_{q}\right)$;

Voltage and power equations are given by:

$$
v_{G}=\omega \sqrt{\phi_{d}^{2}-L^{2} i^{2}} \approx \omega \phi_{d}, P_{G} \approx \frac{3}{2} \omega \phi_{d} \sin \delta i_{G}
$$

Output voltage and speed of generator are quasi-proportionate. Likewise, armature current can act as an input variable to control recovered power. 


\subsection{Intermediate storage capacitor}

Capacitor equation is given by:

$$
v_{C}=\frac{1}{C} \int\left(i_{1}-i_{2}\right) d t
$$

Current $i_{1}$ is extracted from generator trough AC/DC device. Likewise, current $i_{2}$ can act as a second input variable to maintain capacitor voltage around a constant value and, for techno-economic reasons, not exceeding $200 \mathrm{~V}$. Capacitor $\mathrm{C}$ is a smoothing one and its value is high enough to attenuate voltage peaks.

\subsection{Electronic components}

\section{A. Three phase diode bridge rectifier}

With an uncontrolled three-phase bridge rectifier, relation between the fundamental of generator current and rectifier output current is expressed by:

$$
i_{G_{1 R M S}}=\frac{\sqrt{6}}{\pi}<i_{R}>
$$

\section{B. Buck DC/DC converter}

Step-down DC/DC converter, it enables capacitor charging with continuous-mode current. In rolling mean, we have:

$$
i_{1}=\frac{\alpha_{1} V_{R}-v_{C}}{r_{1}}
$$

where $\alpha_{1}$ is the duty cycle and $r_{1}$ is the resistance associated to inductor $L_{1}$. The inductor value $L_{1}$ is set high enough to smooth ripples in current $i_{1}$.

\section{Boost DC/DC converter}

Step-up DC/DC converter, it enables capacitor discharging with continuous-mode current. In rolling mean, we have:

$$
i_{2}=\frac{v_{C}-\left(1-\alpha_{2}\right) V_{M}}{r_{2}}
$$

where $\alpha_{2}$ is the duty cycle and $r_{2}$ is the resistance associated to inductor $L_{2}$. The inductor value $L_{2}$ is set high enough to smooth ripples in current $i_{2}$.

\section{PWM current source inverter}

The inverter bridge consists of six IGBT with appropriate control law. It enables inverting current $I_{2}$ by comparing a sinusoidal current reference (modulating signal) with a high-frequency triangular wave (carrier). The current reference is in phase with voltage to eliminate reactive power exchange with power grid.

\section{Dynamic Modeling}

For system control (Fig. 3), we dispose of two input variables: the currents $I_{1}$ and $I_{2}$. Likewise, we dispose of two state variables: the speed rotation $\Omega$ and capacitor voltage $V_{c}$. With all quantities expressed in small variations, we define state and control vectors such as:

$$
\mathbf{X}=\left(\begin{array}{c}
\dot{\Omega} \\
V
\end{array}\right) \quad \mathbf{U}=\left(\begin{array}{c}
\dot{I}_{1} \\
I
\end{array}\right)
$$




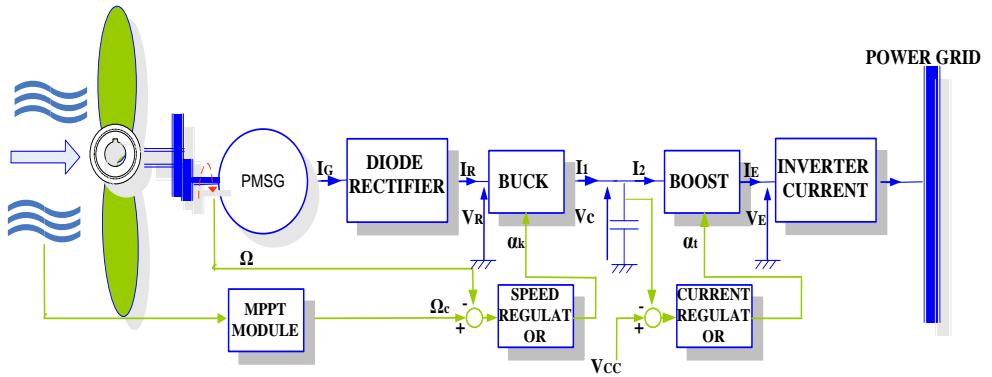

Fig. 3. Main control scheme.

The state-space representation is written in the following form:

$$
\mathbf{X}^{\prime}=\mathbf{A X}+\mathbf{B U}
$$

where

$$
\mathbf{A}=\left(\begin{array}{cc}
A_{11} & -A_{12} \\
0 & 0
\end{array}\right) \quad \mathbf{B}=\left(\begin{array}{cc}
-B_{11} & 0 \\
B_{21} & -B_{22}
\end{array}\right)
$$

Our system verifies controllability and observability conditions but not stability condition (two eigenvalues equal to or greater than 0 ). We look to establish a control law by full-state feedback in order to stabilize the system. The problem consists of determining $\mathbf{K}$ such as:

$$
\mathbf{U}=\mathbf{K X}
$$

where

$$
\mathbf{K}=\left(\begin{array}{cc}
K_{1} & 0 \\
0 & K_{2}
\end{array}\right)
$$

The state matrix of closed-loop system $\mathbf{H}$ is then:

$$
\mathbf{H}=\mathbf{A}+\mathbf{B K}
$$

where

$$
\mathbf{H}=\left(\begin{array}{ll}
H_{11} & H_{12} \\
H_{21} & H_{22}
\end{array}\right)
$$

The characteristic polynomial of $\mathbf{H}$ is given by:

$$
F(s)=|\mathbf{S I}-\mathbf{H}|=s^{2}+a s+b
$$

On the other hand, we look to identify the system with the one stable and defined by $\mathbf{H}_{0}$ such as:

$$
\mathbf{H}_{0}=\left(\begin{array}{cc}
-\lambda_{0} & 0 \\
0 & -\lambda_{0}
\end{array}\right)
$$

This system admits a characteristic polynomial given by:

$$
F_{0}(\mathrm{~s})=s^{2}+2 \lambda_{0} s+\lambda_{0}^{2}
$$

Comparing the two polynomials, we establish that $K_{1}$ is a solution of a quadratic equation such as:

$$
M K_{1}^{2}+N K_{1}+P=0
$$

With $M, N$ and $P$ are functions of $V_{C 0}, I_{10}, \Omega_{0}, J$ and $C$. This quadratic equation enables determining gain values $K_{1}$ and $K_{2}$ of the feedback matrix. 


\section{Algorithm}

The conversion circuit includes two devices disposed in cascade:

- AC/DC device: Automatic adjustment of continuous-mode capacitor charging current $I_{1}$ is performed by the buck converter.

- DC/AC device: Automatic adjustment of continuous-mode capacitor discharging current $I_{2}$ is performed by the boost converter.

The generator control current is performed in full state feedback by pole placement. The results are illustrated by simulations at the end of the paper.

\section{Results and Discussions}

We consider a PMSG with the following characteristics: $16000 \mathrm{~W}, 400 \mathrm{~V}, 50 \mathrm{~Hz}, R_{s}=0.645, L_{1}=$ $0.002228 \mathrm{H}, L_{m d}=0.05297, L_{m q}=0.02518, J=0.1278, f=0.013, p=2$, and the series inductance of isolation transformer is $10^{-4}$. Likewise, we consider a three-bladed wind turbine with the following characteristics: the nominal power $P_{N}=8100 \mathrm{~W}$, the blade radius $R=2,245 \mathrm{~m}$, the gearbox ratio $K_{G}=5$, Wind turbine power occurred for $\lambda_{\text {opt }}=8.1$ and giving $C_{\text {pmax }}=0.48$.

Fig. 4 depicts power curves as functions of generator speed for three significant values of wind speed:

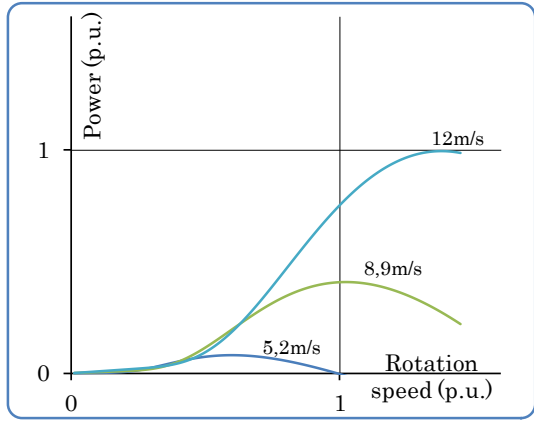

Fig. 4. Power curves as functions of rotation speed.

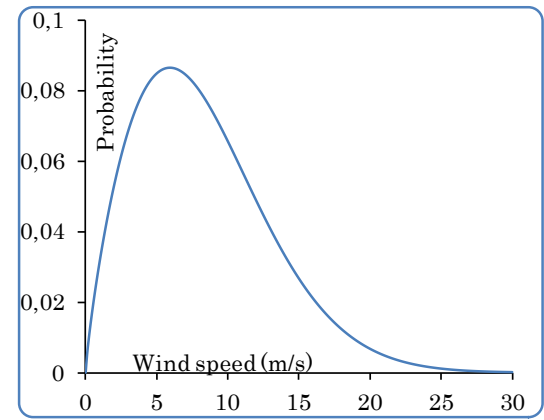

Fig. 5. Weibull distribution of the wind.

Theses curves show that:

- Maximum power is equal to nominal power and occurs at a wind speed of $12 \mathrm{~m} / \mathrm{s}$ when rotation speed is 1.38 p.u.

- Maximum power is equal to 0.40 p.u. at a wind speed of $8.9 \mathrm{~m} / \mathrm{s}$ when rotation speed is 1 p.u.

- At a wind speed of $5.2 \mathrm{~m} / \mathrm{s}$, wind turbine stops working when rotation speed is equal to 1 p.u. (for instance, direct connection case) and maximum power occurs at a rotation speed of 0.6p.u.

On the other hand, we consider the following parameter values for Weibull distribution (Fig. 5): $C=9$, $3 \mathrm{~m} / \mathrm{s}, K=1$, 8 , we obtain the following characteristics:

$$
\langle\mathrm{V}\rangle: 8,3 \mathrm{~m} / \mathrm{s}, F(5,2)=0,30
$$

In the case of direct connection, our wind turbine will stop working for perhaps $30 \%$ of time. For illustrative purposes, we consider a wind speed profile as given:

$$
V(t)=\left\{\begin{array}{l}
12 \mathrm{~m} / \mathrm{s} \text { for } 0 \leq t \leq 6 \mathrm{~s} \\
8,9 \mathrm{~m} / \mathrm{s} \text { for } 6 \leq t \leq 9 \mathrm{~s} \\
5,2 \mathrm{~m} / \mathrm{s} \text { for } 9 \leq t \leq 12 \mathrm{~s}
\end{array}\right.
$$

The Fig. 6 depicts the simulation results of wind turbine simultaneously in start-up phase and production region. 

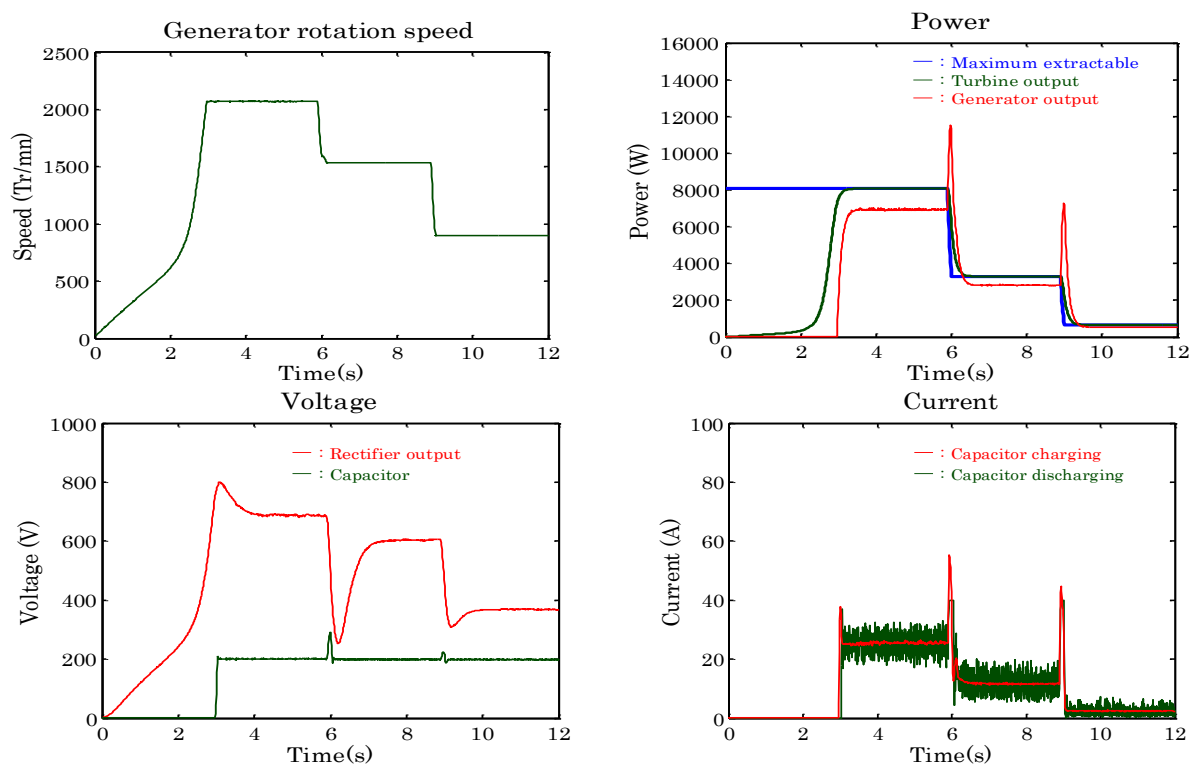

Fig. 6. Simulation results of wind turbine generation for variable wind profile.

\section{Conclusion}

Our MPPT approach is proving satisfactory in terms of fastness of convergence, stability and requirements of wind turbine starting. The proposed method ensures a non-stop production. In start-up phase, there is no need to perform a heavy synchronizing and coupling procedure such as in direct connection. Furthermore, the use of a non-controlled rectifier and a buck converter confers reliable and slow-cost characters to our conversion device. Nonetheless, adoption of standard electric characteristics, both for generator and electronic components, may be damaging in term of dispersion of energy.

\section{References}

[1] Infield D, Freris L. Les energies renouvelables pour la production d'électricité', Techniques et Ingénierie, Dunod/Dunod l'usine nouvelle, 2013.

[2] Jeong HG, Seung RH, Lee KB. An improved maximum power point tracking method for wind power systems. Energies, 2012; 5(5): 1339-1354.

[3] Kazmi SMR, Goto HJ, Ichinokura O. A novel algorithm for fast and efficient speed-sensorless maximum power point tracking in wind energy conversion systems. IEEE Trans. Ind. Electron., 2011; 58(1):29-36.

[4] Moor GD, Beuks HJ. Maximum power point trackers for wind turbines. In: Proc of Power Electronics Specialist Conference (PESC), Aachen, Germany, 2004:1699-1702.

[5] Nakamura T, Morimoto S, Sanada M, Takeda Y. Optimum control of IPMSG for wind generation system. In: Proc of Power Conversion Conference (PCC), Osaka, Japan, 2002:1435-1440.

[6] Datta RV, Ranganathan T. A method of tracking the peak power points for a variable speed wind energy conversion system. IEEE Trans. on Energy Conversion, 2003; 18(1):163-168.

[7] Lampola P. Direct driven, low-speed permanent-magnet generator for wind power applications. Acta Politechnica Scandinaviica, electrical engineering series, no. 101, ESPOO 2000; Published by the Finnish academies of technology.

[8] Beltran B, Ahmed-Ali T, El Hachemi Benbouzid M. Sliding mode power control of variable-speed wind energy conversion systems. IEEE Transactions on Energy Conversion, 2008; 23(2):551-558.

[9] Li X, Xu W, Yu X, Feng Y. Sliding mode control of wind energy generation systems using PMSG and input-output linearization. Presented at: the 31st Chinese Control Conference, Hefei, China, 2012.

[10] Jirutitijaroen P. Average power in the wind energy estimate, lectures notes on sustainable energy systems. National University of Singapore, 2010. 